\title{
FIRST RESPONSE OF EMERGENCY HEALTH CARE SYSTEM AND LOGISTICS SUPPORT IN AN EARTHQUAKE
}

\author{
Kenan Ahmet Turkdogan', Semih Korkut ${ }^{2} \odot$, Elif Arslan ${ }^{3}$, Mustafa Kerem Ozyavuz ${ }^{3}$ \\ 'University of Health Science, Bagcilar Training and Research Hospital, Istanbul, Turkey \\ ${ }^{2}$ University of Health Sciences, Kartal Lütfi Krrdar Training and Research Hospital, Department of Emergency Medicine, Kartal, Istanbul, Turkey \\ ${ }^{3}$ Provincial Health Directorate of Istanbul, Department of Emergency Health Services Bakirkoy, Istanbul, Turkey
}

\begin{abstract}
BACKGROUND: An earthquake is an event that differs from any other disaster because it requires a multidisciplinary approach and affects all the people in the region where it occurs. The presented research aims to present healthcare, search and rescue, logistics and support to the magnitude 6.6 Elazığ earthquake by literature sight. This research also provides analysis of local and nearby support provided by Disaster and Emergency Management Authority (DEMA) (AFAD), 112 Emergency Health Services and National Medical Rescue Team (NMRT) (UMKE), equipment, timely manner and staff in the earthquake of Elazıg on 24.01.2020.
\end{abstract}

MATERIAL AND METHODS: A total of 1942 people, including 120 NMRT Teams (821 NMRT staff) and 276 staff 112 Ambulance teams, were assigned for medical rescue.

RESULTS: Victims: 12 injured and 5 exitus, who were triaged by 112 and NMRT teams, were pulled from the wreckage and transported to the hospitals within the first 30 minutes.

CONCLUSION: As in the Elazığ earthquake, the coordinated and cooperative work of all search and rescue and first aid teams of the region appeared to be one of the most important factors in reducing the mortality and morbidity of earthquake victims and maintaining life comfort.

KEY WORDS: equipment, timely manner, 112, UMKE, AFAD, logistic, staff

Disaster Emerg Med J 2021; 6(2): 63-69

\section{INTRODUCTION}

Earthquakes are natural disasters that have a great social impact as they damage infrastructures and cause many deaths [1]. Rapid response after disasters is critical for emergency logistics since emergency aid in the affected areas is required immediately. This issue has recently raised concerns as the outbreak of natural and man-made disasters (earthquakes, terrorist acts, tsunamis) [2] attracted attention.

Post-disaster early response is vital. As a result of the observations made during the earthquakes in Tangshan - China (1976), Campania-Irpinia - Italy
(1980) and Armenia (1988), 85-95\% of the victims trapped in damaged buildings were rescued within 24 hours. The rates of pulling victims alive after 24 hours are low. It was detected in the post-earthquake studies in Turkey and China that unfortunately less than $50 \%$ of the trapped victims were found alive between 24-hours interval after the earthquake. Time is even more important for the victims with conditions such as hemopneumothorax or limb crush injury [3] that can be treated and recovered.

This study aims to present the importance of coordinated and cooperative work of search and 
rescue of first aid teams in reducing the mortality and morbidity of earthquake victims.

\section{MATERIAL AND METHODS}

A magnitude 6.6 earthquake with a surface depth of $5 \mathrm{~km}$ epicentre of which was Elazığ Sivrice and which lasted 22 seconds occurred on Friday, January 24,2020 , at 20:55.

Starting from the first report after the earthquake the authors retrospectively evaluated the first case given by authorities, moving to the hospital, rescuing, identifying and moving the disaster victims, the hospital treatment processes, determining tent areas, the cooperative work of 112, NMRT and DEMA officers of the region and from the support provinces, examining patients and 112 files and photo images.

\section{RESULTS}

After the magnitude 6.6 earthquake that lasted 22 seconds and the epicentre of which was Sivrice, the first call came from Mustafa Paşa District Tahir Şaşmaz Street at 20:56. The Emergency Health Station Team No. 1, which was 2.680 meters away from the location, was the first 112 team to arrive there in 4 minutes. Intense radio talks started from this minute. A number of calls reached the command control centre (CCC) in two hours on the day of the earthquake (Fig. 1). It is seen that the number of calls increased by $8-9$ times. There was a total of 39112 stations in Elazığ province, 13 in the centre and 16 in the districts.

After the earthquake report, 112 CCC started to receive an increased number of calls. Calls continued to be received from the moment of the earthquake. 412 calls were answered from the time of the in- cident, from 20:55 to 21:55 (the first 60 minutes) (Graph 1 and 2). In addition, medical-based calls and non-medical calls were answered completely, and the other team directions were made. Due to this volume, CCC announced the immediate operating of all NMRT and 112 teams. Graph 1 and 2 show calls received by CCC every 2 hours after the earthquake that happened at 20:55.

Since busy radio communication was predicted from that minute, a mobile repeater was established in a suitable location that could overlook the city, and contacts were provided by offering NMRT teams the possibility of communication between the headquarters and themselves by establishing a different channel than the existing 112 channel. Then, the teams were followed by including the Mobile Command and Control Centre vehicles in the system.

The triage of the injured was done by 112 and NMRT teams that reached the wreckage areas. 112 teams were ordered by CCC via radio announcement to take the injured people to the most appropriate facility accordingly to the victim's condition. In the first 30 minutes after the earthquake, 12 injured and 5 exitus were rescued from the wreckage and transported to the hospitals.

A total of 30 injured people was rescued from the wreckage and transported to the hospitals in Elazığ province: 19 victims to Elazığ State City Hospital and 11 victims to Firat University Hospital.

All staff alerted the Ministry of Health with the earthquake message received from DEMA after the earthquake, and a total of 1942 people were assigned for medical rescue; 120 in NMRT Teams and 821 in NMRT staff. A total of 276112 Ambulances and 1121 of 112 staff from across the country, especially from nearby support provinces (Tab. 1), were directed for logistics support (Tab. 2). Sent equipment allowed to establish in the province a mobile

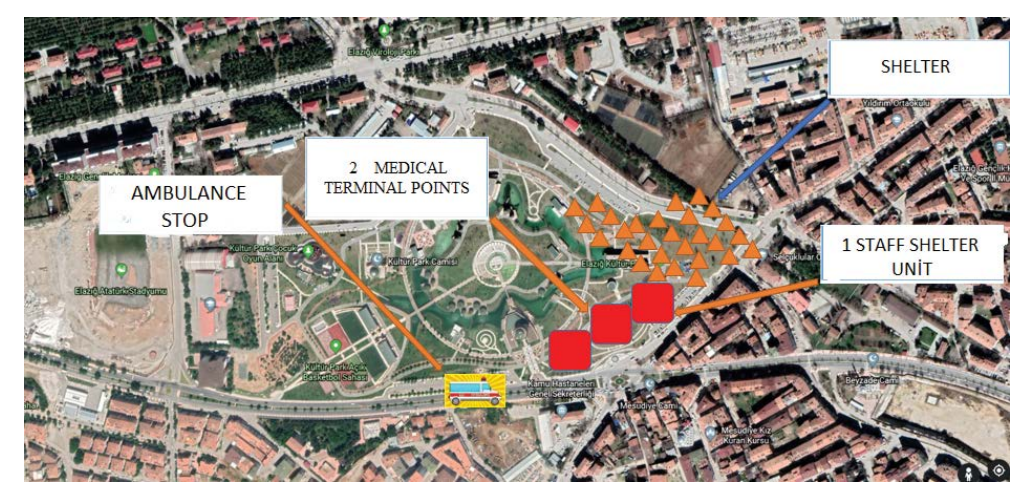

FIGURE 1. The map showing medical terminal points settled in Kültürpark, tent cities and staff accommodation tents 


\begin{tabular}{|c|c|c|c|c|c|c|c|c|c|}
\hline Number & Province & $\begin{array}{c}\text { NMRT } \\
\text { (UMKE) }\end{array}$ & $\begin{array}{c}112 \\
\text { Ambulance }\end{array}$ & $\begin{array}{l}\text { NMRT } \\
\text { Staff }\end{array}$ & $\begin{array}{c}112 \\
\text { Staff }\end{array}$ & $\begin{array}{l}\text { Additional } \\
\text { UMKE Staff }\end{array}$ & $\begin{array}{l}\text { Total } \\
\text { Staff }\end{array}$ & Departure & Arrive \\
\hline 1st Support Province & MALATYA & 1 & 20 & 5 & 60 & & 65 & $00: 10$ & $01: 19$ \\
\hline 1st Support Province & TUNCELI & 1 & 7 & 5 & 21 & & 26 & $21: 30$ & $22: 30$ \\
\hline 1st Support Province & BINGÖL & 2 & 7 & 10 & 21 & & 31 & 21:08 & $22: 18$ \\
\hline 2nd Support Province & DIYARBAKIR & 4 & 30 & 26 & 94 & 20 & 140 & $21: 15$ & $22: 38$ \\
\hline 2nd Support Province & BATMAN & 4 & 4 & 20 & 12 & 3 & 35 & $21: 30$ & $12: 00$ \\
\hline 2nd Support Province & MARDIN & 1 & 2 & 5 & 6 & & 11 & $22: 00$ & $00: 40$ \\
\hline 2nd Support Province & SiliRT & 2 & 2 & 10 & 3 & 4 & 17 & $22: 30$ & $02: 00$ \\
\hline 2nd Support Province & ŞIRNAK & 2 & 2 & 10 & 6 & 3 & 19 & $23: 15$ & $03: 45$ \\
\hline 2nd Support Province & ERZINCAN & 1 & 5 & 5 & 15 & & 20 & $22: 15$ & $01: 00$ \\
\hline 2nd Support Province & BAYBURT & 2 & 2 & 10 & 6 & & 16 & $22: 10$ & $02: 30$ \\
\hline 2nd Support Province & ERZURUM & 2 & 3 & 7 & 9 & & 16 & $21: 20$ & $00: 34$ \\
\hline 2nd Support Province & KARS & 2 & 5 & 10 & 15 & & 25 & $22: 45$ & $02: 55$ \\
\hline 2nd Support Province & IĞDIR & 1 & 1 & 5 & 3 & & 8 & $22: 25$ & $06: 40$ \\
\hline 2nd Support Province & ARDAHAN & 1 & 1 & 5 & 3 & & 8 & 23:19 & $05: 26$ \\
\hline 2nd Support Province & SIVAS & 3 & 3 & 15 & 9 & 8 & 32 & 23:00 & $02: 25$ \\
\hline 2nd Support Province & TOKAT & 1 & 2 & 5 & 6 & & 11 & $22: 35$ & $05: 25$ \\
\hline 2nd Support Province & MUŞ & 2 & 3 & 10 & 9 & & 19 & $21: 22$ & $00: 12$ \\
\hline 2nd Support Province & BiTLIS & 2 & 6 & 10 & 18 & & 28 & $22: 40$ & $02: 20$ \\
\hline 2nd Support Province & VAN & 2 & 4 & 10 & 18 & 4 & 32 & $21: 37$ & $02: 38$ \\
\hline 2nd Support Province & HAKKARI & 1 & 2 & 5 & 6 & & 11 & $22: 40$ & $07: 50$ \\
\hline 2nd Support Province & K.MARAŞ & 1 & 8 & 5 & 24 & & 29 & $22: 00$ & $02: 20$ \\
\hline 2nd Support Province & GAZIANTEP & 2 & 3 & 10 & 9 & 2 & 21 & $21: 45$ & 05.00 \\
\hline 2nd Support Province & ADIYAMAN & 2 & 2 & 10 & 6 & & 16 & $21: 25$ & $00: 15$ \\
\hline 2nd Support Province & S.URFA & 2 & 2 & 10 & 6 & 2 & 18 & $21: 45$ & $01: 40$ \\
\hline 2nd Support Province & KiLIS & 1 & 3 & 5 & 9 & 2 & 16 & $00: 30$ & $05: 30$ \\
\hline
\end{tabular}

Table 2. The table showing logistic support and numbers
\begin{tabular}{|l|c|c|}
\hline \multicolumn{1}{|c|}{ Logistic Support Equipment } & Provinces & Number \\
\hline Helicopter Ambulance & Malatya 2, Sivas 1 & 3 \\
\hline Plane Ambulance & Ankara & 1 \\
\hline Mobil Call centre Vehicle & Samsun, Malatya, Diyarbakır, Konya, Gaziantep & 5 \\
\hline Logistic Vehicle & Gaziantep & 10 \\
\hline Truck & Diyarbakır & 9 \\
\hline Lorry & Diyarbakır & 5 \\
\hline Unit of field Hospital & Gaziantep & 8 \\
\hline Unit of staff shelter & Mersin, Gaziantep, Diyarbakır, Ankara & 4 \\
\hline Mobile Hospital with 50 beds & Trabzon, Antalya, Kayseri ve Eskişehir & 4 \\
\hline Equipment of Mobile Hospital & Şırnak, Mersin, Gaziantep Ve Erzurum & 4 \\
\hline
\end{tabular}


hospital with a total of 250 beds. Table 1 shows first and second support province reaction times and staff support. Table 2 shows all province logistics supports and numbers.

About 5 hours after the earthquake, Province Health Disaster Coordination Centre (PHDCC) was constituted with the subordinate command and control centre by installing a communication radio assembly at a department that wasn't affected by the earthquake in the old Military Hospital for the emergency health services. It was going to be conducted by Provincial Health Directorate, and the management of the crisis was taken over from CCC. The work programme of NMRT and 112 teams coming from out of the province was formed, and their pairing with the command-and-control centre was performed.

As from the 48th hour, 9 medical terminal points were settled (MTP) to satisfy the need-based medical needs and chronic diseases near wreck sites, at collective accommodation areas and thoroughfares and in each point. 1 doctor, 5 NMRT staffs and a 112 team of 3 people gave service (Tab. 3). At the emergency units, 1227 patients in the first 7 days and a total of 3509 patients in 17 days were treated. The map of medical terminal points settled in Kültürpark, tent cities and staff accommodation tents are shown in Figure 1.

In this earthquake which occurred in Elazığ province, the total number of injured was 974; 37 people of whom 18 were female lost their lives. The average age of the victims was 46 .

There were 35 inpatients, 4 of them were in the ICU unit and had 44 different diagnoses. All patients survived treatment procedures.
12580 people ended up homeless due to the earthquake. All victims that were pulled out of wreckages were vaccinated against tetanus. As of 7.02.2020, the total number of collapsed, urgently to be pulled down and heavily damaged buildings was 8519 and the number of collapsed, urgently to be pulled down and heavily damaged individual units was 19821 (Tab. 4). There were 3843 pitched tents and 2453 of them were filled.

\section{DISCUSSION}

While responding to the earthquakes, the two most important aspects are the evacuation of people and the logistics of equipment. Evacuation is the first step of the emergency action phase as it clears the area from the injured and dead. Logistic activities take much more time since they aim to provide necessary disaster relief articles for the people in

Table 4. The table showing the Building Structures
of Elazığ after the Earthquake
\begin{tabular}{|l|c|c|}
\hline \multicolumn{3}{|c|}{ Elazığ Province } \\
\hline & $\begin{array}{c}\text { Number of } \\
\text { Buildings }\end{array}$ & $\begin{array}{c}\text { Separate } \\
\text { Parts }\end{array}$ \\
\hline Undemolished & 25851 & 102812 \\
\hline Minimal damage & 15671 & 66265 \\
\hline Mid damaged & 1540 & 13867 \\
\hline Heavily damaged & 7698 & 17578 \\
\hline Collapse & 263 & 397 \\
\hline Urgently to be pulled down & 558 & 1846 \\
\hline Unstable (non-enterable) & 9571 & \\
\hline Total & 61152 & 202765 \\
\hline
\end{tabular}

\begin{tabular}{|c|c|c|c|c|c|c|c|c|c|}
\hline & \multirow{2}{*}{ Area } & \multirow{2}{*}{ Doctor } & \multicolumn{2}{|c|}{ NMRT (UMKE) } & \multicolumn{2}{|c|}{112} & \multirow{2}{*}{ MTP } & \multirow{2}{*}{ Shelter } & \multirow{2}{*}{ Total Unit } \\
\hline & & & Vehicle & Staff & Vehicle & Staff & & & \\
\hline 1 & Kültür Park Sheltering Area & 2 & 2 & 10 & 2 & 6 & 2 & 1 & 3 \\
\hline 2 & Ahmet Aytar Area & 1 & 1 & 5 & 1 & 3 & 1 & 0 & 1 \\
\hline 3 & Cumhuriyet Fuar Area & 1 & 1 & 5 & 1 & 3 & 1 & 1 & 2 \\
\hline 4 & Mustafa Paşa District Area & 1 & 1 & 5 & 1 & 3 & 1 & 1 & 2 \\
\hline 5 & Sürsürü District Area & 1 & 1 & 5 & 1 & 3 & 1 & 0 & 1 \\
\hline 6 & Sanayi District Area & 1 & 1 & 5 & 1 & 3 & 1 & 0 & 1 \\
\hline 7 & Gezin Waist & 1 & 1 & 5 & 1 & 3 & 1 & 0 & 1 \\
\hline 8 & Sivrice District & 1 & 1 & 5 & 1 & 3 & 1 & 0 & 1 \\
\hline \multicolumn{2}{|c|}{ Total } & 9 & 9 & 45 & 9 & 27 & 9 & 2 & 11 \\
\hline
\end{tabular}


the affected area and transport the injured people to the hospitals or emergency medical units in the affected area. Therefore, planning logistic activities adequately at the phase of responding to an earthquake may decrease human life loss at a vast scale in earthquakes.

The basis of logistics is based on transporting the supplied correct products and equipment at the right time and amount, at a convenient place and to the right people. Disaster logistics is the process of controlled planning and applying goods, support, and related knowledge to meet the needs of people in need to the very last needed point [4]. This process includes logistic activities such as supplying necessary materials (inbound logistics), storing for use when necessary, transporting to related places when necessary (outbound logistics) and tracking as in Business Logistics. However, the application area of Disaster Logistics is much more difficult than Business Logistics in terms of current conditions. Especially a great amount of uncertainty prevails [5] in regards to what is going to be transported, when, how much, where, and how often - this process shows very rapid alterations. Transporting all kinds of necessary support, equipment and services to the disaster victims completely and punctually most of the time in long distances in instantly changing conditions becomes more of an issue. Moreover, such disasters affect transportation infrastructure. Inefficacy of airlines or maritime lines because of confluence, infrastructure failures at highways and railways, and the height limits at tunnels or bridges are examples of what prevents carrying out logistic activities effectively [4]. For this reason, alternative means of transportation, transportation routes and distribution channels should be determined according to different scenarios [6]. For example, in an earthquake that occurred in China in 2008, 150 tons of material were sent to the disaster area by air in one day by 19 helicopters and 6 cargo planes along with 5800 medical and rescue units [7]. In the Elazığ earthquake, logistics support of the disaster area was provided co-ordinately both by air and overland.

Collective human movements following disasters can cause significant increases in morbidity and mortality. Collective human movements can seriously complicate the distribution of the planned aid, needs assessments, and transportation of the planned service. It is difficult to intervene for help without information about the location of the af- fected people [8]. Various projects can be prepared for the implementation of this real-time method, which can make a great contribution to coordinating the search, rescue and first aid, evacuation, and services in Turkey. This may enable transferring the right support to the right people at the right point. In the Elazığ earthquake, the establishment of MTPs in safe places near the wreck areas and near the busiest places of the centre increased the functionality.

Apart from trauma, the most common reason for late mortality after the earthquake is rhabdomyolysis caused by crush syndrome. Acute renal failure following a crush is one of the life-threatening complications and is a reversible treatable condition.

Other complications that may develop after a crush are sepsis, ARDS, DIC, bleeding, hypovolemic shock, heart failure, arrhythmia, electrolyte imbalance and psychological trauma. General disaster algorithms are based on operation plans, transportation, hospitalization, organizing medical staff, early surgery, and the triage strategy for medical intervention. Sever et al. stressed that crush syndrome and kidney failure are as important as general disaster algorithms [9]. They stated that mortality will decrease in health services with appropriate treatment protocols. This study reveals that these complications were noted in the hospitalized cases and none was mortal.

The magnitude 7.2 earthquake that occurred in Van on 23rd October 2011 caused the death of 604 people. 72242 places were detected as ruined and severely damaged [10]. In the Elazığ earthquake, 37 people were killed, and 7961 places were detected as ruined and severely damaged even though the severity was different. The high number of damaged and ruined buildings in Van suggests that the buildings were not built earthquake resistant, and loss of lives was high accordingly.

An increase in 112 calls after the earthquake, triage, and patient registration problems as a result of the increase of inpatient admissions to emergencies, insufficient space to examine the patients, communication problems, increased application of non-earthquake victim patients and problems in patient transport are among the problems that occurred within the first 24-48 hours in emergency services [11-16]. MTPs were established to avoid similar problems in the emergency services of the hospitals in Elazığ and patients were looked after there. There was no registration problem for the patients who applied to the hospitals. 
When the post-earthquake admissions to the services were examined in the Marmara earthquake, the Orthopaedics and Traumatology Clinics took place on the top and while 147 of the 330 wounded were hospitalized in the Orthopaedics and Traumatology Clinic, other patients were hospitalized in the general surgery, plastic surgery, and cardiothoracic surgery services [17]. It was observed that most of the patients hospitalized in Kartal Training and Research Hospital after the Marmara earthquake were in the orthopaedic and traumatology service and 96 of the 160 surgeries were performed for orthopaedic reasons, while other surgeries were laparotomy, tube thoracostomy, head and facial bones fixation [11].

In the Gujarat earthquake in India, orthopaedic injuries were at the forefront in 234 (51\%) of the wounded [18]. In the Van earthquake, most of the cases were patients of Orthopaedics and Traumatology [10]. In the presented study, 15 of the 35 hospitalized patients were followed up in the Orthopaedics service and were determined as following the literature.

In the magnitude 7.2 earthquake that took place on October 23, 2011, 37 people who were pulled in the Erciş district lost their lives in the hospitals where they were treated. In the Elazığ earthquake, no one died during the treatment. Although the intensities were different, it is believed that immediate treatment and subsequent treatment methods may have caused this difference.

When the post-earthquake deaths are examined, it draws attention that $50 \%$ of the deaths are from the young population between the ages of 20-40. Most of the deaths in the Sultandağı earthquake are in the group over 65 years old [19].

In the Elazığ earthquake, the average age of the deceased was 46 . The authors believe that what affects the average age of the affected population is whether the region where the earthquake occurred is urban or rural. This will change the needs for prevention and treatment in both acute and chronic periods.

In the Erciş earthquake, 159 NMRT and 7 healthcare teams reached the scene in the first 6 hours. This shows how successfully the mobility and organization capability of Emergency Healthcare Services was organised, even though it was at night.

The authors' biggest wish is that such disasters like earthquakes that deeply affect the entire society never happen. In Turkey which is in the 1st-degree seismic zone, the Elazığ earthquake will probably be followed by others. Therefore, an appropriate preliminary preparation must be made and DEMA-NMRT, NMRT-112, 112-hospital, intra-hospital and inter-hospital communication and effective triage should be given importance. It should be ensured that all healthcare staff is prepared for such disasters by conducting both in-house and inter-institutional practices as in the disasters. As in the Elazığ earthquake, both regional and national effective healthcare organization will help keep disaster losses at a minimum level.

\section{REFERENCES}

1. Heindl S, Binder C, Desel $H$, et al. [Etiology of initially unexplained confusion of excitability in deadly nightshade poisoning with suicidal intent. Symptoms, differential diagnosis, toxicology and physostigmine therapy of anticholinergic syndrome]. Dtsch Med Wochenschr. 2000; 125(45): 1361-1365, doi: 10.1055/s-2000-8178, indexed in Pubmed: 11109424.

2. Southgate HJ, Egerton M, Dauncey EA. Lessons to be learned: a case study approach. Unseasonal severe poisoning of two adults by deadly nightside (Atropa belladonna). J R Soc Promot Health. 2000; 120(2): 127-130, doi: 10.1177/146642400012000212, indexed in Pubmed: 10944889.

3. Trabattoni G, Visintini D, Terzano GM, et al. Accidental poisoning with deadly nightshade berries: a case report. Hum Toxicol. 1984; 3(6): 513-516, doi: 10.1177/096032718400300607, indexed in Pubmed: 6526400.

4. Joshi P, Wicks AC, Munshi SK. Recurrent autumnal psychosis. Postgrad Med J. 2003; 79(930): 239-240, doi: 10.1136/pmj.79.930.239, indexed in Pubmed: 12743348.

5. Krenzelok E. Aspects ofDaturapoisoning and treatment. Clinical Toxicology. 2010; 48(2): 104-110, doi: 10.3109/15563651003630672.

6. Burns MJ, Linden $\mathrm{CH}$, Graudins $\mathrm{A}$, et al. A comparison of physostigmine and benzodiazepines for the treatment of anticholinergic poisoning. Ann Emerg Med. 2000; 35(4): 374-381, doi: 10.1016/\$01960644(00)70057-6, indexed in Pubmed: 10736125.

7. Anonymous. Physostigmine. Lexi-Comp Online. Hudson, $\mathrm{OH} .2000$.

8. American Hospital Formulary Service. American Journal of Health-System Pharmacy. 1959; 16(10): 541-541, doi: 10.1093/ajhp/16.10.541.

9. Demirhan A, Tekelioğlu ÜY, Yıldız İ, et al. Anticholinergic Toxic Syndrome Caused by Atropa Belladonna Fruit (Deadly Nightshade): A Case Report. Turk J Anaesthesiol Reanim. 2013; 41(6): 226-228, doi: 10.5152/TJAR.2013.43, indexed in Pubmed: 27366377.

10. Lange A, Toft P. Poisoning with nightside, Atropa belladona. Ugeskr Laeger. 1990; 152: 1096.

11. Perlik-Gattner I. Atropa belladona poisoning suggesting severe post - traumatic brain damage. Przegl Lek. 1997; 54: 464-65. 
12. Lamminpää $A$, Kinos M. Plant poisonings in children. Hum Exp Toxicol. 1996; 15(3): 245-249, doi: 10.1177/096032719601500310, indexed in Pubmed: 8839213.

13. Schneider $F$, Lutun $P$, Kintz $P$, et al. Plasma and urine concentrations of atropine after the ingestion of cooked deadly nightshade berries. J Toxicol Clin Toxicol. 1996; 34(1): 113-117, doi: 10.3109/15563659609020245, indexed in Pubmed: 8632502.

14. MS Bektaş, F Aktar, A Güneş, Ü Uluca, S Gülşen, K Karaman. Atropa belladona poisoning in chilhood. West Indian Med J Doi: 0. 7727/ wimj. ; 2015: 457.
15. Caksen H, Odabaş D, Akbayram S, et al. Deadly nightshade (Atropa belladonna) intoxication: an analysis of 49 children. Hum Exp Toxicol. 2003; 22(12): 665-668, doi: 10.1191/0960327103ht4040a, indexed in Pubmed: 14992329.

16. Cikla U, Turkmen S, Karaca Y, et al. An Atropa belladonna L. poisoning with acute subdural hematoma. Hum Exp Toxicol. 2011; 30(12): 1998-2001, doi: 10.1177/0960327111407225, indexed in Pubmed: 21540312 